\title{
Stomalı Hastaların Yaşam Kalitesi ve Öz Yeterlilik Düzeylerinin Belirlenmesi
}

\section{The Determination of Self-Efficacy and Quality of Life in Patients with Stoma}

\author{
Zekiye Yaşar ${ }^{1}$, Hülya Üstündağ ${ }^{2 *}$ \\ ${ }^{1}$ Sağlık Bilimleri Üniversitesi Sultan Abdülhamid Han Eğitim ve Araştırma Hastanesi, İstanbul, Türkiye \\ ${ }^{2}$ İstanbul Bilgi Üniversitesi Sağlık Bilimleri Fakültesi Hemşirelik Bölümü, İstanbul, Türkiye \\ e-mail: hulya.ustundag34@gmail.com, zekiyeyasar34@hotmail.com \\ ORCID: 0000-0002-5717-3178 \\ ORCID: 0000-0001-6119-8573 \\ *Sorumlu yazar/ Corresponding Author: Hülya Üstündağ \\ Gönderim Tarihi / Received: 13.10.2020 \\ Kabul Tarihi / Accepted: 23.11.2020 \\ DOI: $10.34087 /$ cbusbed. 813080
}

Giriş ve Amaç: Bu çalışma stomalı hastaların yaşam kalitesinin ve öz yeterlilik düzeylerinin belirlenmesi amacıyla yapild1.

Gereç ve Yöntemler: Tanımlayıcı tipte olan araştırmanın örneklemini Ocak-Eylül 2018 tarihleri arasında bir üniversite hastanesinin genel cerrahi ana bilim dalı ve Stomaterapi ünitesinde takip edilen 195 hasta oluşturdu. Araştırma verileri literatür doğrultusunda araştırmacılar tarafından hazırlanan Hasta Bilgi Formu, Umut Merkezi Ostomi Yaşam Kalitesi Ölçeği (UM-OYKÖ), Genel Öz Yeterlilik Ölçeği (GÖYÖ) kullanılarak toplandı. Veriler, yüzdelik, ortalama, standart sapma, student t-testi ve ANOVA testi, Pearson Korelasyon testi ile analiz edildi.

Bulgular: Hastaların yaş ortalaması 58.12 \pm 11.09 olup, \%61,5'i erkektir. Umut merkezi ostomi yaşam kalitesi ölçeği toplam puan ortalaması 262,12 $\pm 49,05$ olarak belirlendi. Ölçeğin alt boyutlarından en yüksek ve en düşük puan

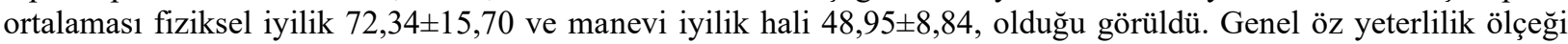
toplam puan ortalaması 30,36 $\pm 7,80$ dir. Umut merkezi ostomi yaşam kalitesi ölçeği toplam puanı ile stomalı hastaların cinsiyet $(p=0,012)$, medeni durum $(p=0,001)$, eğitim durumu $(p=0,000)$, stoma bakımını kendisi yapması $(p=0,000)$ ve komplikasyon gelişme durumu $(\mathrm{p}=0,014)$ arasında anlamlı fark olduğu saptandı. Genel öz yeterlilik ölçeği toplam puanı ile stomalı hastaların medeni durumları $(\mathrm{p}=0,027)$, eğitim durumu $(\mathrm{p}=0,018)$, stoma bakımını kendisi yapması $(p=0,000)$, arasında anlamlı fark olduğu saptandı. Stomalı hastaların, genel öz yeterlilik ölçeği toplam puanı ile umut merkezi ostomi yaşam kalitesi ölçeği toplam puanı ve tüm alt boyutları arasında ileri derecede anlamlı pozitif korelasyon saptand1.

Sonuç: Stoma bakım hemşireleri bireye özgü hemşirelik bakımı planlarken, yaşam kalitesini ve öz-yeterliliğini olumsuz etkileyen faktörleri dikkate almalıdırlar.

Anahtar kelimeler: Hemşirelik bakımı, Öz yeterlilik, Stoma, Yaşam kalitesi.

Abstract
Objective: The aim of this study was to determine of self-efficacy and quality of life in patients with stoma.
Material and Methods: This descriptive study was conducted between January - September 2018 in the stomatherapy
unit and general surgery outpatient clinic of a university hospital. The study sample included 195 patients agreeing to
participate. Patient information form, the City of Hope- Quality of life-Ostomy Questionnaire (COH-QOL-OQ) and
the General Self-Efficacy Scale(GSE) were used for data collection. Descriptive statistics, t-test, one-way analysis of
variance,and Pearson's correlation coefficient were used to evaluate the data.
Results: The mean age of the patients was $58.12 \pm 11.09$ years and $61,5 \%$ of them were male. The mean score of City
of Hope- Quality of life-Ostomy Questionnaire was $262,12 \pm 49,05$. The highest and lowest scores were obtained for
the subscales physiological well-being $(72,34 \pm 15,70)$ and spiritual well-being $(48,95 \pm 8,84)$, respectively. The mean
score of General Self-Efficacy was $30,36 \pm 7,80$. There was a statistically significant difference between the mean score
of City of Hope- Quality of life-Ostomy Questionnaire and gender ( $\mathrm{p}=0,012)$, marital status ( $\mathrm{p}=0,001)$, educational
status ( $\mathrm{p}=0.000)$, ability for self care of stoma ( $\mathrm{p}=0,000)$ and occurence of stomal complication $(\mathrm{p}=0.014)$. There was


a statistically significant difference between the mean score of General Self-Efficacy Scale and marital status $(\mathrm{p}=0,027)$, educational status $(\mathrm{p}=0.018)$ and ability for self care of stoma $(\mathrm{p}=0,000)$. A positive significant correlation between the total and sub-scale scores of City of Hope- Quality of life-Ostomy and General Self-Efficacy were found. Conclusion: Stomacare nurses should take into account factors that negatively affect patients' quality of life and selfefficacy while planning individual nursing care.

Keywords: Nursing care, Ostomy, Quality of life, Self-efficacy.

\section{Giriş}

Stoma oluşturulmasını gerektiren en yaygın neden kolorektal kanserler olmakla beraber inflamatuar barsak hastalıkları, travma, divertikülit, ileus, ve familyal adenomatöz polipozis koli gibi hastalıklarda da açılmaktadır [1-3]. Stoma oluşturulması ile birlikte bireyin yaşam biçiminde değişiklikler ve stomaya uyum problemleri, beden imajında değişme, istemsiz gaz çıkışı korkusu, sosyal izolasyon, benlik saygısında azalma, aile ve iş yaşantısının olumsuz etkilenmesi, cilt ve seksüel problemler gibi birtakım sorunlarla karşı karşıya kalmaktadır [4-6]. Stoma bireyin yaşam kalitesini ve fiziksel, psikolojik, spirütüel, sosyal tüm yönlerini olumsuz etkilemektedir [7-10]. Geng ve ark. 2017 de yaptıkları çok merkezli çalışmalarında stoma cerrahisinden sonra bireylerin yaşam kaliteleri tüm yönleri ile azalan bir puana sahip olduğunu belirtmişlerdir [11]. Yine Vonk-Klaassen ve ark. yaptıkları sistematik derlemede hem kanser hem de kanser dışı nedenlerle stoma oluşumu sonrası yaşam kalitesinin azaldığını göstermişlerdir [12]. Yaşam kalitesinin geliştirilmesi ve sürdürülmesi hasta, hasta yakınları ve sağlık çalışanlarının en önemli hedefleri arasındadir $[4,5]$

Öz-yeterlilik bireyin herhangi bir durum ya da olay karşısında yapabilecekleri ile ilgili kendini algılama durumudur [13,14]. Bandura tarafından geliştirilmiş bir öğrenme teorisidir. Bireyin öğrenmede başarılı olması, zorluklara rağmen beceriyi uygulama ve sonuçlara ulaşma inancidır [15,16]. Bireylerin sorunla karşılaştıklarında, verdikleri tepkileri, gösterdikleri çabaları, sorunu gidermedeki uğraşları öz yeterlilik düzeylerinden etkilemektedir. Literatürde öz yeterliliğin yüksek olması sağlık davranışlarını değiştirmede önemli bir rol oynadığ yönde etkileyebileceği belirtilmektedir [13,16,17]. Yapılan çalışmalarda daha yüksek öz yeterlik düzeyine sahip bireylerin hastalı sürecinin ve tedavilerinin yönetiminde daha etkili olduğu gösterilmiştir [13,16-18]. Yüksek öz yeterliliğe sahip bireyler çeşitli stres faktörleriyle güvenle başa çıkmak, sağlığı korumak ve sürdürmek için gerekli davranışlarda bulunma olasılıklarının daha yüksek olduğu belirtilmektedir $[13,14,17]$.

Stomalı bireylerin özyeterlilik düzeylerinin ve yaşam kalitesinin iyileştirilmesi için özyeterlilik ve yaşam kalitesi düzeylerinin belirlenmesi ve bunların yükseltilmesine yönelik uygun hemşirelik yöntemlerinin tasarlanması önemlidir.

$\mathrm{Bu}$ çalışma; stomalı hastaların yaşam kalitesini ve öz yeterlilik düzeylerinin belirlemek amacıyla tanımlayıcı ve kesitsel olarak yapıldı.

$\mathrm{Bu}$ amaç doğrultusunda araştırma soruları;
- Stomalı hastaların yaşam kalitesi ve öz yeterlilik düzeyleri nedir?

- Stomalı hastaların yaşam kalitesi ve öz yeterlilik düzeylerini etkileyen faktörler nelerdir?

- Stomalı hastaların yaşam kalitesi ve öz yeterlilik düzeyleri arasında bir ilişki var mı?

\section{Materyal ve Metot}

\subsection{Araştırmanın Tipi}

Çalışma tanımlayıcı ve kesitsel olarak yapıldı.

2.2. Araştırmanın Evreni ve Örneklemi

Araştırmanın evrenini bir üniversite hastanesinin genel cerrahi ana bilim dalı ve Stomaterapi ünitesinde takip edilen stomalı hastalar oluşturdu. Çalışmaya; 18-85 yaş arası, iletişim kurulabilen, intestinal stoması olan, terminal dönemde olmayan, çalışmaya katılmayı kabul eden, nörolojik ve psikiyatrik sorunu olmayan hastalar dahil edildi.

\subsection{Verilerin Toplanmast}

Çalışmada, literatür 1şığında hazırlanan 'Hasta Bilgi Formu' ve Umut Merkezi Yaşam Kalitesi Ölçeği (UMOYKÖ), Genel Öz Yeterlilik Ölçeği (GÖYÖ) kullanıldı. Hasta Bilgi Formu: Veri toplama aracı olarak araştırmacı tarafindan literatür bilgileri doğrultusunda geliştirilen anket formu kullanıldı. Formda hastanın yaş, cinsiyet, eğitim durumu, medeni durum, çalışma durumu, sigara/alkol kullanma durumu, kronik hastalık durumu, hastalık tanısı, ameliyat aciliyet türü, stoma bakımını kendisinin yapma durumu ve stoma komplikasyonu gelişme durumu gibi sorular yer aldı.

Umut Merkezi Ostomi Yaşam Kalitesi Ölçeği [UMOYKÖ]; City of Hope Pain and Pallaiative Care Resource Center tarafından geliştirilmiş Grant ve arkadaşlar1 $^{19}$ tarafından ostomili bireyler için düzenlenmiştir. Ölçek ostomili bireylerin yaşam kalitesini fiziksel, psikolojik, sosyal, manevi yönden değerlendirmeye olanak sağlamaktadır. ${ }^{19}$ Ölçeğin dört alt boyutu bulumaktadır. Fiziksel İyilik Hali 1-11 maddeler; Psikolojik İyilik Hali 12-24 maddeler; Sosyal Kayg1 2536 maddeler; Manevi İyilik Hali 37-43 maddeler ile ölçülmektedir. Puanlanmasında 1. maddeden 12. Maddeye kadar; 15, 18, 19, 22-30, 32-34, 37 maddelerin puanları ters çevrilerek yorumlanmaktadır. Ölçek, likert tipi 0-10 arasında puanlandırılmaktadır. Puan yükseldikçe yaşam kalitesinin yükseldiği belirtilmektedir. Ölçeğin bir kesme puanı yoktur. Ölçeğin Türkçe'ye uyarlanması, geçerlik/güvenirlik çalışmalarını Erol ve Vural tarafindan yapılmıştır [20]. Geçerlilik güvenirlik çalışması sonucunda ölçeğin Cronbach Alfa İç Tutarlılık Katsayısı 0.92 olarak bulunmuştur [20]. Bu çalışmada Cronbach's Alpha değeri 0.89 olarak bulunmuştur. 
Genel Öz Yeterlilik Ölçeği [GÖYÖ]; Mathias Jeruselam ve Ralf Schawazzer tarafindan Almanya'da geliştirilmiştir. İlk geliştirildiğinde 20 maddeden oluşan ölçek, 1981 yılında aynı araştırmacılar tarafından revize edilerek madde sayısı 10'a indirilmiştir. Genel Öz Yeterlilik ölçeği Alpay tarafından geçerlilik güvenilirlik çalışması yapılarak Türk toplumuna uyarlanmıştır [21]. Türkçe'ye uyarlanan 10 ifade bulunmakta ve her biri 1'den 4'e kadar değişen puanlar almaktadır. Ölçekten elde edilen en düşük puan 10 , en yüksek puan ise 40 olarak değerlendirilmektedir. Ölçek puanı arttıkça öz yeterlilik puanı artmaktadır. Geçerlilik güvenirlik çalışması sonucunda ölçeğin Cronbach's Alpha değeri 0.83 olarak bulunmuştur [21]. Bu çalışmada Cronbach's Alpha değeri 0.93 olarak bulunmuştur

2.4. Veri Toplama Yöntemi

Veriler Ocak-Eylül 2018 tarihleri arasında İstanbul'da bulunan bir üniversite hastanesinin genel cerrahi ana bilim dalı kliniği, polikliniği ve stomaterapi ünitesinde takip edilen en az iki aydır intestinal stomaya sahip olan, gerekli açıklamalar yapıldıktan sonra çalışmaya katılmayı kabul eden hastalarla, yüz yüze görüşme yöntemi kullanılarak toplandı.

\subsection{Verilerin Analizi}

Çalışmada elde edilen veriler SPSS (Statistical Package for Social Sciences) for Windows 23.0 programı kullanılarak analiz edildi. Verileri değerlendirirken tanımlayıcı istatiksel metotlar (sayı, yüzde)uygulandı, ilişkisel karşılaştırma için student's t testi, tek yönlü ANOVA, ve iki ölçeğin karşılaştırılmasında Pearson Korelasyon testi kullanıldı. Anlamlılık $p<0,05$ olarak alındi.

2.6. Çalışmanın Etik Yönü

Çalışmaya başlamadan önce için bir üniversitenin Etik Kurulu'ndan (No:2017-87) ve araştırmanın yapıldığı üniversite hastanesi genel cerrahi anabilim dalından gerekli izinler alındı. Ayrıca araştırmaya dâhil edilen hastalardan sözel ve yazılı izin alındı. Çalıșma, Helsinki Deklarasyonu Prensipleri'ne uygun olarak yapıldı.

\section{Bulgular ve Tartışma \\ 3.1 Bulgular}

Çalışma kapsamına alınan hastaların yaş ortalamaları $58.12 \pm 11.09$ olup, \%61,5'inin erkek, \%82,6's1 evli, \%43,1'i ilkokul mezunu, \%77,9'unun çalışmadığ1, \%84,6'sinın sigara, \%95,4'ünün ise alkol kullanmadığı saptandı. Çalışmaya katılan bireylerin \%53,8'inin kronik hastalığı olmadığı, \%74,9’unun tanısının kanser olduğu, \%77,9'unun ameliyatının planlanmış olduğu, \%93,8'inin stoma bakımını kendisi yaptığ1, \%69,2'sinde stoma komplikasyonu geliştiği saptandı (Tablo 1).

Çalışmaya katılan hastaların umut merkezi ostomi yaşam kalitesi ölçeği toplam puan ortalaması 262,12 $\pm 49,05$ olarak belirlendi. Ölçeğin alt boyutlarından puan ortalamas1 sirasiyla fiziksel iyilik $72,34 \pm 15,70$, psikolojik iyilik 72,01 $\pm 20,38$, sosyal kayg1 69,99 $\pm 18,76$, manevi iyilik hali $48,95 \pm 8,84$, olduğu görüldü. Genel öz
Tablo 1. Demografik Özelliklerin Dağılımı (N=195)

\begin{tabular}{|c|c|c|}
\hline Özellikler & $\mathbf{n}$ & $\%$ \\
\hline Yaş Ort \pm SS & $58.12 \pm 11.09$ & \\
\hline \multicolumn{3}{|l|}{ Cinsiyet } \\
\hline Kadin & 75 & 38,5 \\
\hline Erkek & 120 & 61,5 \\
\hline \multicolumn{3}{|l|}{ Medeni Durum } \\
\hline Evli & 161 & 82,6 \\
\hline Bekar & 34 & 17,4 \\
\hline \multicolumn{3}{|l|}{ Eğitim Düzeyi } \\
\hline Okur-Yazar Değil & 17 & 8,7 \\
\hline Okur-Yazar & 3 & 1,5 \\
\hline İlkokul & 84 & 43,1 \\
\hline Ortaokul & 28 & 14,4 \\
\hline Lise & 42 & 21,5 \\
\hline Üniversite & 21 & 10,8 \\
\hline \multicolumn{3}{|l|}{ Çalışma Durumu } \\
\hline Çalışıyor & 43 & 22,1 \\
\hline Çalışmıyor & 152 & 77,9 \\
\hline \multicolumn{3}{|l|}{ Sigara } \\
\hline Kullaniyor & 30 & 15,4 \\
\hline Kullanmiyor & 165 & 84,6 \\
\hline \multicolumn{3}{|l|}{ Alkol } \\
\hline Kullaniyor & 9 & 4,6 \\
\hline Kullanmiyor & 186 & 5,4 \\
\hline \multicolumn{3}{|l|}{ Kronik Hastalık } \\
\hline Var & 90 & 46,2 \\
\hline Yok & 105 & 53,8 \\
\hline
\end{tabular}

$\begin{array}{lrr}\text { Hastalık Tanısı } & & \\ \text { Kanser } & 146 & 74,9 \\ \text { Kanser değil } & 49 & 25,1 \\ & & \\ \text { Ameliyat Türü } & & \\ \text { Planlanmış } & 152 & 77,9 \\ \text { Acil } & 43 & 22,1\end{array}$

$\begin{array}{lcc}\text { Stoma Bakımını Yapan } & & \\ \text { Kendisi } & & \\ \text { Birinin Yardımıyla } & 97 & 49,7 \\ \text { Tamamen Başkası } & 68 & 34,9 \\ \text { [Eş- Çocuk] } & 30 & 15,4 \\ & & \\ \text { Stoma komplikasyonu } & & \\ \text { Gelişti } & 135 & 69,2 \\ \text { Gelişmedi } & 60 & 30,8\end{array}$

yeterlilik ölçeği puan ortalaması $30,36 \pm 7,80$ olarak belirlendi (Tablo 2).

Tablo 2. Stomalı Hastaların UM-OYKÖ ve GÖYÖ Puan Ortalamaları 


\begin{tabular}{lllll}
\hline Ölçekler ve altboyutları & Ort \pm SS & Min & Max & Puan-Aralığı \\
\hline Ostomi Yaşam Kalitesi & $262,12 \pm 49,05$ & 88,00 & 378,00 & $0-420$ \\
Fiziksel İyilik & $72,34 \pm 15,70$ & 10,00 & 110,00 & $0-110$ \\
Psikolojik İyilik & $72,01 \pm 20,38$ & 7,00 & 128,00 & $0-130$ \\
Sosyal Kayg1 & $69,99 \pm 18,76$ & 10,00 & 108,00 & $0-120$ \\
Manevi İyilik & $48,95 \pm 8,84$ & 9,00 & 69,00 & $0-70$ \\
Öz yeterlilik & $30,36 \pm 7,80$ & 10,00 & 40,00 & $10-40$ \\
\hline
\end{tabular}

UM-OYKÖ: Umut Merkezi-Ostomi Yaşam Kalitesi Ölçeği GÖYÖ: Genel Öz Yeterlilik Ölçeği

Tablo 3. Demografik özellikler ile UM-OYKÖ ve GÖYÖ toplam ve alt boyut puan ortalamalarının karşılaştırılması ( $\mathrm{N}=195)$

\begin{tabular}{|c|c|c|c|c|c|c|}
\hline \multirow{3}{*}{$\begin{array}{l}\text { Demografik } \\
\text { özellikler }\end{array}$} & \multicolumn{5}{|c|}{ UM-OYKÖ } & \multirow{3}{*}{$\begin{array}{l}\text { GÖYÖ } \\
\text { Öz-Yeterlilik } \\
\text { Ort } \pm \text { Ss }\end{array}$} \\
\hline & $\begin{array}{l}\text { Genel Yaşam } \\
\text { Kalitesi }\end{array}$ & $\begin{array}{l}\text { Fiziksel } \\
\text { Íyilik }\end{array}$ & $\begin{array}{l}\text { Psikolojik } \\
\text { İyilik }\end{array}$ & Sosyal Kaygı & Manevi İyilik & \\
\hline & Ort $\pm \mathrm{Ss}$ & Ort \pm Ss & Ort \pm Ss & Ort \pm Ss & Ort \pm Ss & \\
\hline \multicolumn{7}{|l|}{ Cinsiyet } \\
\hline Kadın & $250,96 \pm 47,05$ & $68,66 \pm 14,54$ & $67,09 \pm 19,77$ & $67,97 \pm 18,15$ & $49,20 \pm 8,43$ & $29,08 \pm 8,13$ \\
\hline Erkek & $269,10 \pm 49,17$ & $74,65 \pm 16,01$ & $75,08 \pm 20,23$ & $71,25 \pm 19,09$ & $48,80 \pm 9,12$ & $31,16 \pm 7,51$ \\
\hline $\mathrm{t}$ & $-2,549$ & $-2,628$ & $-2,706$ & $-1,191$ & $-0,134$ & $-1,720$ \\
\hline $\mathrm{p}$ & 0,012 & 0,009 & 0,007 & 0,235 & 0,893 & 0,085 \\
\hline \multicolumn{7}{|l|}{ Medeni Durum } \\
\hline Evli & $257,04 \pm 47,68$ & $71,12 \pm 15,34$ & $69,29 \pm 19,06$ & $69,64 \pm 18,45$ & $48,41 \pm 8,66$ & $29,75 \pm 8,07$ \\
\hline Bekar & $286,17 \pm 48,97$ & $78,14 \pm 16,28$ & $84,88 \pm 21,74$ & $71,64 \pm 20,34$ & $51,50 \pm 9,36$ & $33,23 \pm 5,63$ \\
\hline $\mathrm{t}$ & $-3,221$ & $-2,399$ & $-4,225$ & $-0,564$ & $-2,386$ & $-2,205$ \\
\hline $\mathrm{p}$ & 0,001 & 0,017 & 0,000 & 0,573 & 0,017 & 0,027 \\
\hline \multicolumn{7}{|l|}{ Eğitim Durumu } \\
\hline Okur-yazar Değil & $211,58 \pm 53,24$ & $59,23 \pm 12,51$ & $49,23 \pm 19,12$ & $59,82 \pm 20,55$ & $43,29 \pm 10,33$ & $22,88 \pm 9,26$ \\
\hline Okur-yazar & $231,00 \pm 20,66$ & $67,66 \pm 7,02$ & $61,66 \pm 18,14$ & $49,33 \pm 14,29$ & $52,33 \pm 2,08$ & $27,66 \pm 4,04$ \\
\hline İlkokul & $260,85 \pm 47,00$ & $72,94 \pm 13,39$ & $70,71 \pm 19,04$ & $70,59 \pm 18,42$ & $48,60 \pm 8,81$ & $29,94 \pm 8,37$ \\
\hline Ortaokul & $281,96 \pm 38,62$ & $74,89 \pm 14,69$ & $80,14 \pm 18,27$ & $75,07 \pm 15,38$ & $51,85 \pm 7,50$ & $32,71 \pm 6,38$ \\
\hline Lise & $271,40 \pm 49,44$ & $73,64 \pm 19,13$ & $78,04 \pm 19,83$ & $72,09 \pm 20,47$ & $49,09 \pm 8,39$ & $32,38 \pm 5,16$ \\
\hline Üniversite & $267,57 \pm 41,81$ & $75,28 \pm 17,35$ & $74,19 \pm 17,44$ & $67,80 \pm 16,28$ & $50,28 \pm 9,31$ & $31,33 \pm 7,30$ \\
\hline $\mathrm{F}$ & 5,759 & 2,940 & 7,111 & 2,400 & 13,203 & 13,618 \\
\hline $\mathrm{p}$ & 0,000 & 0,014 & 0,000 & 0,039 & 0,022 & 0,018 \\
\hline \multicolumn{7}{|l|}{ Çalışma Durumu } \\
\hline Çalışıyor & $270,48 \pm 47,27$ & $74,62 \pm 17,42$ & $78,11 \pm 17,74$ & $69,32 \pm 19,34$ & $49,86 \pm 8,15$ & $31,74 \pm 6,97$ \\
\hline Çalışmıyor & $259,76 \pm 49,43$ & $71,70 \pm 15,17$ & $70,28 \pm 20,79$ & $70,18 \pm 18,65$ & $48,69 \pm 9,04$ & $29,97 \pm 8,00$ \\
\hline $\mathrm{t}$ & 1,268 & 1,079 & 2,248 & $-0,264$ & $-0,826$ & $-0,884$ \\
\hline $\mathrm{p}$ & 0,206 & 0,282 & 0,026 & 0,792 & 0,409 & 0,377 \\
\hline
\end{tabular}

F: One-Way ANOVA t:t-Testi

UM-OYKÖ: Umut Merkezi-OstomiYaşam Kalitesi Ölçeği GÖYÖ: Genel Öz Yeterlilik Ölçeği 
Çalışmada stomalı hastaların cinsiyetleri ile ostomi yaşam kalitesi toplam puanı $(p=0,012)$ ve aynı ölçeğin alt boyutlarından fiziksel iyilik ( $p=0,009)$, psikolojik iyilik $(\mathrm{p}=0,007)$ puanı arasında anlamlı fark olduğu saptandı. Cinsiyet ile öz yeterlilik arasında anlamlı fark olmadığı belirlendi. (Tablo 3).

Stomalı hastaların medeni durumları ile ostomi yaşam kalitesi kalitesi toplam puanı $(\mathrm{p}=0,001)$, ve alt gruplarından fiziksel iyilik $(\mathrm{p}=0,017)$, psikolojik iyilik $(\mathrm{p}=0,000)$, manevi iyilik $(\mathrm{p}=0,017)$, puanı arasında anlamlı fark olduğu ve genel öz yeterlilik $(p=0,027)$ puanı arasında istatistiksel olarak anlamlı fark olduğu saptandı (Tablo 3). Çalışmaya katılan hastaların eğitim durumu ile ostomi yaşam kalitesi toplam puanı $(\mathrm{p}=0,000)$, ve tüm alt boyutları puanı arasında, istatistiksel olarak fark olduğu saptandı. (sırasıyla fiziksel iyilik $\mathrm{p}=0,014$, psikolojik iyilik $\mathrm{p}=0,000$, sosyal kayg1 $\mathrm{p}=0,039$, manevi iyilik $\mathrm{p}=0,022$ ve genel öz yeterlilik $\mathrm{p}=0,018$ ) (Tablo 3). Çalışmadaki hastaların çalışma durumları ile ostomi yaşam kalitesi alt boyutu olan psikolojik iyilik puanı $(\mathrm{p}=0,026)$, arasında istatistiksel olarak anlamlı fark olduğu saptandı. Genel yaşam kalitesi toplam puanı alt boyutlarından fiziksel iyilik, sosyal kaygı, manevi iyilik, ve genel öz yeterlilik puanları arasında istatistiksel olarak anlamlı fark olmadığı saptandı ( $\mathrm{p}>0,05)$. (Tablo 3).

Çalışmaya katılan hastaların tanıları ile ostomi yaşam kalitesi, alt boyutları ve genel öz yeterlilik puanları arasında istatistiksel olarak anlamlı fark olmadığ saptandı ( $>>0,05)$ (Tablo 4). Çalışmadaki hastaların acil ya da planlı olarak gerçekleştirilen ameliyat şekilleri ile ostomi yaşam kalitesi toplam puanı $(p=0,018)$, ve alt boyutu olan fiziksel iyilik puanı $(\mathrm{p}=0,046)$, arasında istatistiksel olarak anlamlı fark olduğu saptandı. (Tablo 4). Çalışmaya katılan stomalı hastaların, stoma bakımı kendisinin yapıp yapmaması ile ostomi yaşam kalitesi toplam puanı $(\mathrm{p}=0,000)$, ve tüm alt boyutları arasında (sırasıyla fiziksel iyilik $\mathrm{p}=0,006$, psikolojik iyilik $(\mathrm{p}=0,000)$, sosyal kayg1 $\mathrm{p}=0,000$, manevi iyilik $\mathrm{p}=0,000)$ ve genel öz yeterlilik puanı $(\mathrm{p}=0,000)$, arasında istatistiksel olarak fark olduğu saptand1. (Tablo 4). Çalışmadaki hastaların stoma komplikasyonu gelişme durumu ile ostomi yaşam kalitesi toplam puanı $(\mathrm{p}=0,014)$, ve alt boyutu olan fiziksel iyilik puanı $(\mathrm{p}=0,000), \quad$ arasinda istatistiksel olarak anlamlı fark olduğu saptandı. Genel öz yeterlilik puanları arasında istatistiksel olarak anlamlı fark olmadığı saptandı. (Tablo 4).

Tablo 4. Stomayla ilgili özellikler ile UM-OYKÖ ve GÖYÖ toplam ve alt boyut puan ortalamalarının araştırılması $(\mathrm{N}=195)$

\begin{tabular}{|c|c|c|c|c|c|c|}
\hline \multirow{2}{*}{ Özellikler } & \multicolumn{5}{|c|}{ UM-OYKÖ } & \multirow{2}{*}{$\begin{array}{l}\text { GÖ YÖ } \\
\text { Öz-Yeterlilik } \\
\text { Ort } \pm \text { Ss }\end{array}$} \\
\hline & $\begin{array}{l}\text { Genel Yaşam } \\
\text { Kalitesi } \\
\text { Ort } \pm \text { Ss }\end{array}$ & $\begin{array}{l}\text { Fiziksel İyilik } \\
\text { Ort } \pm \mathrm{Ss}\end{array}$ & $\begin{array}{l}\text { Psikolojik İyilik } \\
\text { Ort } \pm \text { Ss }\end{array}$ & $\begin{array}{l}\text { Sosyal Kaygı } \\
\text { Ort } \pm \text { Ss }\end{array}$ & $\begin{array}{l}\text { Manevi İyilik } \\
\text { Ort } \pm \text { Ss }\end{array}$ & \\
\hline \multicolumn{7}{|l|}{ Stoma bakımı yapan } \\
\hline Kendisi & $285,23 \pm 35,87$ & $75,53 \pm 14,27$ & $83,53 \pm 15,88$ & $75,58 \pm 15,86$ & $51,42 \pm 6,56$ & $34,02 \pm 5,31$ \\
\hline Birinin Yardımıyla & $246,10 \pm 52,95$ & $70,73 \pm 17,03$ & $64,73 \pm 18,08$ & $65,11 \pm 21,27$ & $46,55 \pm 9,69$ & $28,52 \pm 8,00$ \\
\hline $\begin{array}{l}\text { Tamamen Başkası } \\
\text { [Eş- Çocuk] }\end{array}$ & $223,73 \pm 37,99$ & $65,70 \pm 14,76$ & $51,23 \pm 13,13$ & $62,96 \pm 16,24$ & $46,40 \pm 11,07$ & $22,70 \pm 7,26$ \\
\hline $\mathrm{F}$ & 30,836 & 5,270 & 55,229 & 9,472 & 15,451 & 49,375 \\
\hline $\mathrm{p}$ & 0,000 & 0,006 & 0,000 & 0,000 & 0,000 & 0,000 \\
\hline \multicolumn{7}{|l|}{ Tanı } \\
\hline Kanser & $262,91 \pm 50,04$ & $71,86 \pm 16,35$ & $72,30 \pm 20,60$ & $70,34 \pm 18,44$ & $49,01 \pm 8,78$ & $30,56 \pm 7,80$ \\
\hline Kanser değil & $256,77 \pm 46,38$ & $73,77 \pm 13,62$ & $71,12 \pm 19,87$ & $68,93 \pm 19,85$ & $48,77 \pm 9,10$ & $29,77 \pm 7,86$ \\
\hline$t$ & 0,387 & $-0,734$ & 0,352 & 0,454 & $-0,343$ & $-0,676$ \\
\hline $\mathrm{p}$ & 0,699 & 0,464 & 0,726 & 0,650 & 0,732 & 0,499 \\
\hline \multicolumn{7}{|l|}{ Ameliyat durumu } \\
\hline Planlanlı & $266,53 \pm 44,17$ & $73,53 \pm 14,43$ & $73,47 \pm 19,25$ & $71,24 \pm 17,56$ & $49,28 \pm 7,62$ & $30,63 \pm 7,79$ \\
\hline Acil & $246,53 \pm 61,47$ & $68,13 \pm 19,13$ & $66,83 \pm 23,48$ & $65,58 \pm 22,17$ & $47,76 \pm 12,27$ & $29,41 \pm 7,86$ \\
\hline $\mathrm{t}$ & 2,390 & 2,007 & 1,898 & 1,756 & $-0,066$ & $-1,114$ \\
\hline $\mathrm{p}$ & 0,018 & 0,046 & 0,59 & 0,081 & 0,947 & 0,265 \\
\hline \multicolumn{7}{|c|}{ Komplikasyon gelişme durumu } \\
\hline Gelişti & $274,98 \pm 43,77$ & $78,63 \pm 15,40$ & $75,10 \pm 19,44$ & $73,03 \pm 17,68$ & $49,40 \pm 8,84$ & $31,23 \pm 6,88$ \\
\hline Gelişmedi & $256,41 \pm 50,33$ & $69,55 \pm 15,05$ & $70,63 \pm 20,70$ & $68,64 \pm 19,13$ & $48,75 \pm 8,87$ & $29,97 \pm 8,17$ \\
\hline $\mathrm{t}$ & 2,472 & 3,857 & 1,415 & 1,513 & $-0,498$ & $-0,088$ \\
\hline $\mathrm{p}$ & 0,014 & 0,000 & 0,159 & 0,132 & 0,612 & 0,930 \\
\hline
\end{tabular}

F: One-Way ANOVA t:t-Testi

UM-OYKÖ: Umut Merkezi-Ostomi Yaşam Kalitesi Ölçeği GÖYÖ: Genel Öz Yeterlilik Ölçeğ 
Çalışmaya katılan stomalı bireylerin, ostomi yaşam kalitesi düzeyleri ile genel öz yeterlilik düzeyleri arasındaki ilişkiyi değerlendirmek üzere yapılan korelasyon analizi sonucunda genel öz yeterlilik düzeyi ile ostomi yaşam kalitesi ve tüm alt boyutları arasında ileri derecede anlamlı olarak pozitif korelasyon saptandı. Genel öz yeterlilik düzeyi arttıkça ostomi yaşam kalitesi(r=0,583 $\mathrm{p}<0,001)$, Fiziksel iyilik $(\mathrm{r}=0,307$ $\mathrm{p}<0,001)$, psikolojik iyilik( $\mathrm{r}=0,646 \mathrm{p}<0,000)$, sosyal kayg1 $(\mathrm{r}=0,377 \mathrm{p}<0,000)$, manevi iyilik $(\mathrm{r}=0,479$ p<0,000), düzeylerinin puanı arttığı görüldü. (Tablo 5).

Tablo 5. UM-OYKÖ ve GÖYÖ arasındaki ilişki

\begin{tabular}{lcc}
\hline UM-OYKÖ & \multicolumn{2}{c}{ GÖYÖ } \\
\hline Ostomi Yaşam & 0,583 & $\mathbf{p}$ \\
Kalitesi & & 0,000 \\
Fiziksel İyilik & 0,307 & 0,000 \\
Psikolojik İyilik & 0,646 & 0,000 \\
Sosyal Kaygi & 0,377 & 0,000 \\
Manevi İyilik & 0,479 & 0,000
\end{tabular}

Pearson Korelasyon Testi

UM-OYKÖ: Umut Merkezi-Ostomi Yaşam Kalitesi Ölçeği GÖYÖ: Genel Öz Yeterlilik Ölçeği

\subsection{Tartışma}

Yaşam kalitesi incelemeleri, tedavi ve bakım uygulamalarının yaşamın tüm alanlarına olan etkisini, hastanın bakış açısı, algıları ve hissettikleri ile değerlendirme olanağı sunmaktadır $[5,7,9]$. Yapılan çalışmalarda stoma cerrahisi sonrasında hastaların yaşam kalitelerinin olumsuz yönde etkilendiği ve stoma ile yaşama uyumda sorunlar yaşadıkları ortaya konulmuştur [22-24]. Stomalı bireyin öz-yeterlilik algısı arttırılarak, mevcut duruma uyumu, oluşabilecek komplikasyonları yönetebilmesi sağlanarak yaşam kalitesi yükseltilebilir. Çalışma kapsamına alınan stomalı hastaların Umut Merkezi Ostomi Yaşam Kalitesi Ölçeğinden aldıkları toplam puan $(262,12 \pm 49,05)$ ortanın biraz üstünde olduğu görüldü. En düşük alt boyut puan ortalamasının manevi iyilik alt boyutundan alındığ $[48,95 \pm 8,84]$, bunu artan puan ortalamaları ile sosyal kaygı, psikolojik iyilik, fiziksel iyilik alt boyutlarının izlediği ve en yüksek puan ortalamasının fiziksel iyilik alt boyutunda [72,34 $\pm 15,70]$ olduğu görüldü. UM-OY Ölçeğinden alınabilecek puanlar dikkate alındığında, ölçeğin tüm alt boyutların, ortalama değere yakın bir puana sahiptir. Stomalı hastaların yaşam kalitesinin orta düzeyde, en fazla etkilenen yaşam alanının manevi iyilik hali olduğu görüldü. Khalilzadeh ve arkadaşlarının İran'da stomalı hastalarla yaptığı çalışmada yaşam kalitesi toplam puanının orta düzeyde olduğu, ölçek alt boyutu olan psikolojik sağlığın en yüksek, manevi sağlığın en düşük puanı olduğunu bildirdiler [23]. Zhang ve ark., Geng ve ark., $\mathrm{Xu}$ ve ark., yaptıkları çalışmalarında, stoma ameliyatından sonra hastalarının yaşam kalitesin toplam puan ve alt boyut puanlarının orta düzeyde olduğunu belirtmişlerdir $[7,11,13]$. Benzer çalışmalarda cerrahi sonrası ostomi yaşam kalitesi ve ölçeğin alt grupları puanlarının orta düzeyde olduğu görülmektedir $[8,17,23,26]$. En fazla etkilenen yaşam alanının manevi iyilik hali olması hastaların dini uygulamalarını gerçekleştirmeleri ile ilgili sıkıntı yaşamalarına bağlı olduğu düşünülmektedir. Yaşam kalitesi ile ilgili sistematik incelemede Müslüman olan hastalarda stomanın dini ritüeller üzerindeki etkisi ile yaşam kalitesi arasında önemli ilişki olduğu belirtilmektedir [24]. Yine Çavdar ve ark. yaptığı çalışmada stomanın hastaların oruç tutmak ve namaz kılmak gibi dini ibadetleri yerine getiremediklerini ya da yerine getirmede bazı zorluklar yaşadıklarını ve hastaların önemli ölçüde etkilediğini bildirdiler [25].

Araştırma kapsamına alınan hastaların cinsiyete göre UM-OYKÖ alt boyut puan ortalamalarına bakıldığında; genel olarak kadın hastalarda tüm alt boyut puan ortalamalarının düşük olduğu gözlendi Ostomi yaşam kalitesi toplam puanı, Fiziksel iyilik, psikolojik iyilik, alt boyutu puan ortalamaları istatistiksel açıdan anlamlı fark bulundu. Geng ve arkadaşlarının yaptığ 1 çalışmada erkek stomalı hastaların yaşam kalitesi puanlarının daha yüksek olduğu aralarında istatistiksel olarak anlamlı fark olduğunu bildirmişlerdir [11]. Sapilewska ve arkadaşlarının erkek stomalı hastaların yaşam kalitesi puanlarının kadınlardan daha yüksek olduğunu, belirtmişlerdir [26]. Çalışma sonuçları benzer çalışmalarla uyumlu bulundu. Toplumun kadınlara yüklediği aile üyelerinin bakımı ev işleri gibi rol ve sorumlulukları yerine getirememe düşünceleri, kadınların, yaşam kalitelerinin erkeklere oranla daha düşük olmasına neden olabilmektedir.

Çalışmada, eğitim durumu ile UM-OYKÖ toplam puan ve tüm alt boyut puan ortalaması arasında istatistiksel açıdan anlamlı bir fark olduğu ve eğitim düzeyi yükseldikçe ölçek puan ortalamalarının da yükseldiği saptandı. Zhang ve ark., Sapilewska ve ark. yaptığı çalışmada, stomalı hastalarda eğitim düzeyi yükseldikçe yaşam kalitesinin arttığı aralarında istatistiksel olarak anlamlı fark olduğu bildirilmektedir [7,26]. Çalışma bu yönüyle önceki çalışmalarla uyumludur [7,26]. Eğitim durumunun bireylerin kişisel gelişimi ve yaşam kaliteleri üzerinde doğrudan etkili olduğu, bireylerin iyi bir eğitime sahip olmaları ile birlikte nitelikli, sosyal koşulları daha iyi olan konumda bulunmaları yaşam kalitelerini olumlu yönde etkilemektedir.

Çalışmadaki stomalı hastaların medeni durumlarına göre UM-OYKÖ toplam puan, fiziksel iyilik, psikolojik iyilik, manevi iyilik hali ve puan ortalamalarında istatistiksel olarak anlamlı fark olduğu saptandı. Bekar bireylerin puan ortalamalarının daha yüksek olduğu saptandı. 
Santos ve arkadaşları Brezilya'da yaptığı çalışmasında partnere ya da eşe sahip olan stomalı bireylerin yaşam kalitesi puanlarının anlamlı şekilde daha yüksek olduğunu belirttiler [27]. Bu farklılıklar hastaların farklı ülkelerde sosyokültürel özelliklerinin farklı olmasına bağlanabilir. Ülkemizde evli bireylerin aile içindeki rollerine bağlı olarak kendine daha az zaman ayırması, aile içindeki rolünü yeterince yerine getiremediğini, yetersiz kaldığını düşünmesi ya da aile içinde rol değişimi olması nedeni ile yaşam kalitesinin düştüğü şeklinde yorumlanabilir.

Çalışmadaki stomalı hastaların çalışma durumlarına göre UM-OYKÖ alt boyutu olan psikolojik iyilik puan ortalaması arasında istatistiksel olarak anlamlı fark olduğu saptandı. Çalışma hayatında aktif olmanın, üreten bir insan konumunda olmanın getirdiği güven duygusunun bireyin yaşam kalitesinde psikolojik iyilik haline katkı sağladığı düşünülebilinir.

Çalışmada, stoma bakımını yapma durumu ile UMOYKÖ toplam puan ve tüm alt boyut puan ortalaması arasında istatistiksel açıdan anlamlı bir fark olduğu, stoma bakımını kendisi yapan hastanın ölçek puan ortalamalarının daha yüksek olduğu saptandı. Zhang ve arkadaşlarının çalışmasında da stoma bakımını kendisi yapan hastaların yaşam kalitesinin daha yüksek olduğu ve istatistiksel olarak anlamlı fark olduğu ifade edilmiştir [7]. Stomabakım hemşirelerinin hastalarına stomalarını kendi kendilerine yönetmelerini öğretmeleri, bakım konusunda bilgi-beceri kazandırmaları, hastaların karşılaştığ 1 sorunlarla baş etmesi ve yaşam kalitesinin iyileştirilmesi açısından çok önemlidir.

Literatürde stomalı bireylerde stomaya ilişkin komplikasyon oluşumunun yaşam kalitesini olumsuz etkilediği bildirilmektedir [7,28,29]. Bu çalışmada stoma komplikasyonu gelişen bireylerde genel yaşam kalitesi ve alt boyut olan fiziksel iyilik puanları istatistiksel olarak anlamlı fark olduğu saptandı. En sık karşılaşılan komplikasyon peristomal irritasyon [\%60] ve kanama [\%5.6] olduğu belirlendi. Goldstine ve arkadaşlarının yaptığ 1 çalışmada peristomal sızıntı ve peristomal cilt iritasyonunun en s1k görülen komplikasyon olduğu ve yaşam kalitesini önemli ölçüde etkilediğini, yaşam kalitesini bozan stresörler arasında olduğunu belirtmişlerdir [28]. Zhang ve arkadaşları peristomal cilt komplikasyonu gelişen hastaların yaşam kalitesinde azalma olduğu ve istatistiksel olarak fark olduğunu göstermişlerdir [7]. Maydick 230 katılımcı ile yaptığı çalışmasında üçte bir oranında peristomal cilt komplikasyonlarının görüldüğünü ve yaşam kalitesini anlamlı olarak azalttığını bildirmiştir [29]. Stoma bakımındaki teknolojik gelişmelere rağmen hasta, stomaya ilişkin problemlerle karşı karşıya kalabilmektedir. $\mathrm{Bu}$ hastaların yaşam kalitesini iyileştirmek amacıyla daha fazla girişim yapılmasının temel bir zorunluluk olduğu düşünülmektedir.

Literatürde öz-yeterlilik bireylerin kendilerine inancı olarak tanımlanırken, olumlu sağlık davranışlarının başlatılması ve sürdürülmesinde belirleyici olmaktadır. Durumlar ya da olaylar karşısında bireylerin ne hissedeceği, ne düşüneceği ve nasıl davranacağını belirleyen özelliğidir [13,21]. Bu çalışmada genel öz

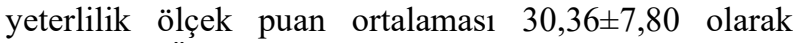
belirlendi. Ölçekten alınması beklenen en yüksek öz yeterlilik puanı 40 olduğu göz önüne alındığında, çalışmada hastaların öz yeterlilik düzeylerinin yüksek olduğu söylenebilir. Xu ve arkadaşlarının 2018 de yaptıkları çalışmada öz-yeterlilik puanları iyi düzeyde olduğunu belirtmişlerdir [13]. Çalışma benzer çalışma sonuçları ile uyumludur $[16,17,18]$.

Öz-yeterliğin doğasının bilişsel olduğu, bilgi yoluyla gelecek etkilere ve değişmeye açık olduğunu belirtilmektedir [21]. İyi eğitim alınması, eğitim düzeyinin yükselmesi bireylerin algılama becerilerini arttırmakta ve hedeflerine daha kolay ulaşmalarını sağlamaktadır. Çalışmadaki hastaların eğitim durumları ile GÖYÖ puan ortalaması arasında istatistiksel olarak anlamlı fark olduğu saptand. Okur-yazar olmayan hastaların öz yeterlilik puanlarının anlamlı derecede düşük olduğu görüldü. Bazalinski ve ark., Su ve ark. Wu ve ark. nın stomalı hastalarla yaptıkları çalışmada eğitim düzeyi düşük olan bireylerin öz yeterlilik düzeylerinin düşük olduğunu bildirmişlerdir $[14,17,18]$. Bu durum eğitim düzeyi yüksek olan bireylerin sağlık hizmetlerine ve bilgiye erişimlerinin daha kolay olması ile açıklanabilir. Eğitim düzeyi arttıkça sağlıkla ilgili farkındalığın artması ekonomik ve sosyal çevre koşullarının daha iyi olması ile ilişkilendirilebileceği düşünülmektedir.

Stomalı hastaların medeni durumları ile GÖYÖ puan ortalamaları arasında istatistiksel olarak anlamlı bir fark olduğu saptandı. Bekar hastaların öz yeterlilik puanlarının evli olanlara göre anlamlı derecede yüksek olduğu görüldü. $\mathrm{Su}$ ve ark. çalışmalarında bekar hastaların evlilere göre öz yeterlilik puanlarının yüksek olduğunu bildirmişlerdir [17]. Bu durum bekar ve çocuk sahibi olmayan hastaların kendilerine daha fazla zaman ayırma imkanlarının olması, stoma bakımı konusunda destek alma olasılıklarının daha sınırlı olması nedeni ile sorumlulukları kendileri almak durumunda kalmaları öz yeterlilik düzeylerinin daha yüksek olduğu ile açıklanabilir.

Hastaların cinsiyet, çalışma durumu ve komplikasyon varlığı ile GÖYÖ puan ortalamaları arasında istatistiksel olarak anlamlı fark bulunamadı. Bazalinski ve ark Su ve ark. araştırmalarında cinsiyetle ile öz yeterlilik arasında istatistiksel olarak anlamlı bir ilişki olmadığını ifade etmişlerdir [14,17]. Çalışma bulguları önceki çalışmalar ile uyumludur.

Stomalı hastaların stoma bakımını yapma durumu ile GÖYÖ puan ortalaması arasında istatistiksel olarak anlamlı bir fark olduğu saptandı. Bu bulgu stoma bakımını kendi yapan bireylerin kendine güven ve kendi kendine yetme durumuna bağlanabilir.

Öz yeterlilik algısında bireyin davranışının başarı ile gerçekleşmesi, bireyin cesaretlenmesine ve öz yeterliliğinin artmasına katkı sağlayabilir. Stomalı hastalarda öz yeterlilik ile yaşam kalitesi ilişkisi incelendiğinde, öz yeterlilik ile genel yaşam kalitesi $[\mathrm{r}=0,583 \mathrm{p}<0,001]$ ve alt grupları olan fiziksel iyilik $[\mathrm{r}=0,307 \mathrm{p}<0,001]$, psikolojik iyilik [r=0,646 $\mathrm{p}<0,001]$, 
sosyal kayg1 $[\mathrm{r}=0,377 \mathrm{p}<0,001]$, manevi iyilik hali $[\mathrm{r}=0,479 \mathrm{p}<0,001]$ arasında pozitif yönde istatistiksel olarak ileri derecede anlamlı bir ilişki olduğu, öz yeterlilik düzeyleri yüksek olan hastaların yaşam kalitesi yüksek olduğu belirlendi. Szpilewska ve ark. yaptıkları çalışmasında stoma oluşumundan sonra stoma varlığını, hastalığını kabul edenlerin yaşam kalitesinin daha yüksek ve istatistiksel olarak anlamlı bir fark olduğunu belirttiler [26]. Xu ve ark., Wu ve ark. çalışmalarında öz yeterlilik ile genel yaşam kalitesi ve alt boyutları arasında pozitif yönde anlamlı korelasyon olduğunu, öz yeterlilik puanı yükseldikçe yaşam kalitesi ve alt boyutlarının puanlarının yükseldiğini bildirdiler $[13,18]$.

Araștırmanın Sinırlılıkları

Araştırma bir üniversite hastanesinde takip edilen, OcakEylül 2018 tarihleri arasında çalışmayı kabul eden stomalı hastalarla sınırlıdır.

\section{Sonuc}

Stomalı hastaların ostomi yaşam kalitesinin orta, genel öz-yeterliliğin iyi düzeyde olduğu belirlendi. Stomalı hastaların cinsiyet, medeni durum, eğitim durumu, stoma bakımını kendisi yapması ve komplikasyon gelişme durumu ile ostomi yaşam kalitesi arasında anlamlı fark olduğu saptandı. Stomalı hastaların medeni durumları eğitim durumu ve stoma bakımını kendisi yapması ile genel öz yeterlilikleri arasında anlamlı fark olduğu görüldü. Stomalı hastaların, genel öz yeterlilik düzeyi arttıkça ostomi yaşam kalitesi ve tüm alt boyut düzeylerinin puanı arttığı belirlendi. Stomabakım hemşirelerinin bireye özgü hemşirelik bakımı planlarken, yaşam kalitesini ve öz-yeterliliğini olumsuz etkileyen faktörleri dikkate almalıdırlar. Bireylerin öz-yeterliliğini geliştirilmesi yönünde desteklenmesi, yaşam kalitesinin artmasında etkili olacaktır.

\section{Referanslar}

1.Wound, Ostomy and Continence Nurses Society; Guideline Development Task Force. WOCN Society Clinical Guideline: Management of the Adult Patient With a Fecal or Urinary OstomyAn Executive Summary, Journal Wound Ostomy Continence Nursing, 2018, 45(1), 50-58.

2. Bray, F, Ferlay, J, Soerjomataram, I, Siegel, R.L, Torre, L.A, Jemal, A, Global cancer statistics 2018: GLOBOCAN estimates of incidence and mortality worldwide for 36 cancers in 185 countries, CA Cancer Journal for Clinicians, 2018, 68(6), 394-424.

3. Ambei, P.C, Kurz, N.R, Nitschke, C, Odeh, S.F, Möslein, G, Zirngibl, H, Intestinal Ostomy, Deutsches Arzteblatt International, 2018, 16(11), 182-187

4. Berti-Hearn, L, Elliott, B, Colostomy Care: A guide for home care clinicians, Home Healthcare Now, 2019, 37(2), 68-78.

5. Vural, F, Erol, F, Ostomili hastalarda yaşam kalitesi nasıl yükseltilir? Dokuz Eylül Üniversitesi Hemșirelik Yüksek Okulu Elektronik Dergisi, 2013, 6(1), 34-39.

6. Üstündağ, H, Demir, N, Zengin, N, Gül, A, Stomalı bireylerde beden imajı ve benlik saygısı, Türkiye Klinikleri Tip Bilimleri Dergisi, 2007, 27(4), 522- 527.

7.Zhang, Y, Xian, H, Yang, Y, Zhang, X, Wang, X, Relationship between psychosocial adaptation and health-related quality of life of patients with stoma: A descriptive, cross-sectional study, Journal of Clinical Nursing, 2019, 28(15-16), 2880-2888.

8. Knowles, S.R, Tribbick, D, Connell, W.R, Castle, D, Salzberg, M, Kamm, M.A, Exploration of Health Status, Illness Perceptions, Coping Strategies, Psychological Morbidity, and Quality of Life in Individuals With Fecal Ostomies,. Journal Wound Ostomy Continence Nursing, 2017, 44 (1), 69-73.
9. Duluklu, B, Celik, S.S, . Effects of lavender essential oil for colorectal cancer patients with permanent colostomy on elimination of odor, quality of life, and ostomy adjustment: A randomized controlled trial, European Journal Oncology Nursing, 2019, 42(1), 90-96.

10. Yilmaz, E, Çelebi, D, Kaya, Y, Baydur, H, A Descriptive, Crosssectional Study to Assess Quality of Life and Sexuality in Turkish Patients with a Colostomy, Ostomy Wound Management, 2017, 63(8), 22-29.

11. Geng, Z, Howell, D, Xu, H, Yuan, C, Quality of Life in Chinese Persons Living With an Ostomy: A Multisite Cross-sectional Study, Journal Wound Ostomy Continence Nursing, 2017, 44(3), 249-256.

12. Vonk-Klaassen, S.M, de Vocht H.M, den Ouden, M.E, Eddes, E.H, Schuurmans, M.J, Ostomy-related problems and t,heir impact on quality of life of colorectal cancer ostomates: a systematic review, Quaity ofl Life Research, 2016, 25(1), 125-133.

13. Xu, S, Zhang, Z, Wang, A, Zhu, J, Tang, H, Zhu, X, Effect of Selfefficacy Intervention on Quality of Life of Patients With Intestinal Stoma, Gastroenteroloji Nursing, 2018, 41(4), 341-346.

14. Bazaliński, D, Sałacińska, I, Więch, P, Kózka M, Life satisfaction and self-efficacy in patients with stoma, Progress Health Sciences, 2014, 4(2), 22-30

15. Bandura, A, Exercise of Personal and Collective Efficacy in Changing Societies. Bandura A. Self-efficacy in changing societies, Cambridge University Pres, New York, 1995:1-45.

16. Su, X, Qin, F, Zhen, L, Ye, X, Kuang, Y, Zhu, M, Yin, X, Wang, H, Self-efficacy and Associated Factors in Patients With Temporary Ostomies, Journal of Wound, Ostomy and Continence Nursing, 2016. 43(6), 623-629.

17. Su, X, Zhen, L, Zhu, M, Kuang, Y, Qin, F, Ye, X, Yin, X, Wang, H, Determinants of self-efficacy and quality of life in patients with temporary enterostomy: a cross-sectional survey, Journal of Clinical Nursing, 2017, 26(3-4), 477-484.

18. Wu, H.K, Chau, J.P, Twinn, S, Self-efficacy and quality of life among stoma patients in Hong Kong, Cancer Nursing, 2007, 30(3), 186-193.

19. Grant, M, Ferrel, B, Dean, G, Uman, G, Chu, D, Krouse, R, Revision and psychometric testing of the city of hope quality of life-ostomy questionnaire, Quality of Life Research, 2004, 13(8), 1445-1457.

20. Erol, F, Vural, F, Umut Merkezi ostomi yaşam kalitesi ölçeği'nin geçerlik ve güvenirliği, Hemşirelikte Araştırma Geliştirme Dergisi, 2012, 14(3), 1-14

21. Alpay, A, Genel özyeterlilik ölçeğinin Türkçe'ye uyarlama çalışması, İnönü Üniversitesi Eğitim Fakültesi Dergisi, 2010, 11(2), 113-131.

22. Xian, H, Zhang, Y, Yang, Y, Zhang, X, Wang, X, A Descriptive, Cross-sectional Study Among Chinese Patients to Identify Factors that Affect Psychosocial Adjustment to an Enterostomy, Ostomy Wound Management, 2018, 64(7), 8-17.

23. Khalilzadeh-Ganjalikhani, M, Tirgari, B, Roudi-Rashtabadi, O, Shahesmaeili, A, Studying the effect of structured ostomy care training on quality of life and anxiety of patients with permanent ostomy, International Wound Journal, 2019, 16(6), 1383-1390

24. Iqbal, F, Kujan, O, Bowley, DM, Keighley, MR, Vaizey, C.J, Quality of Life After Ostomy Surgery in Muslim Patients: A Systematic Review of the Literature and Suggestions for Clinical Practice, Journal Wound Ostomy Continence Nursing 2016, 43(4), 385-391.

25. Cavdar, I, Ozbas, A, Akyuz, N, Findik, U.Y, Kutlu, Y, Religious worship in patients with abdominal stoma: praying and fasting during Ramadan, International Journal Caring Sciences, 2013, 6(3), 516521

26. Szpilewska, K, Juzwiszyn, J, Bolanowska, Z, et al. Acceptance of disease and the quality of life in patients with enteric stoma, Fundacja Polski Przeglad Chirurgiczny, 2018, 90(1), 13-17.

27. Santos, V.L, Augusto, F.S, Gomboski, G, Health-Related Quality of Life in Persons With Ostomies Managed in an Outpatient Care Setting, Journal Wound Ostomy Continence Nursing 2016, 43(2), 158-164.

28. Goldstine, J, Van Hees, R, Van de Vorst, D, Skountrianos, G, Nichols, T, Factors influencing health-related quality of life of those in the Netherlands living with an ostomy, British Journal Nursing, 2019,28(22), S10-S17.

29. Maydick-Youngberg, D, A Descriptive Study to Explore the Effect of Peristomal Skin Complications on Quality of Life of Adults With a Permanent Ostomy, Ostomy Wound Management. 2017, 63(5), 1023 
http://edergi.cbu.edu.tr/ojs/index.php/cbusbed isimli yazarın CBU-SBED başlıklı eseri bu Creative Commons Alıntı-Gayriticari4.0 Uluslararası Lisansı ile lisanslanmıştır.

(c) (7) (8) 